\title{
PENGEMBANGAN INSTRUMEN PENGKAJIAN M3 (METHOD) DALAM MANAJEMEN KEPERAWATAN BERBASIS STANDAR AKREDITASI JOINT COMISSION INTERNATIONAL
}

\author{
Diana Rachmania, Widyasih Sunaringtyas, Dhina Widayati \\ (Stikes Karya Husada Kediri, Jl. Soekarno Hatta No. 07, Pare-Kediri, Jawa \\ Timur) \\ Email: widiana1925@gmail.com
}

\begin{abstract}
ABSTRAK
Tahap pengkajian metode (M3) dalam manajemen keperawatan memerlukan inovasi untuk menyesuaikan dengan perkembangan antara kondisi ruangan dengan keperluan standar akreditasi Rumah Sakit. Tujuan dari penelitian untuk mengembangkan instrumen pengkajian M3 (Method) dalam manajemen keperawatan berbasis standar akreditasi Joint Comission International. Desain Penelitian adalah mix method memadukan pendekatan kualitatif dan kuantitatif. Populasi dalam penelitian ini semua perawat (76) di RS Amelia. Sampel dalam penelitian ini 20 perawat dengan teknik purposive sampling. Tahap 1 peneliti menyusun instrumen melalui small group discussion dengan pihak bidang keperawatan, kepala ruang, dan perawat. Tahap 2 melakukan analisis uji validitas dan reliabitas. Hasil uji validitas menunjukkan instrumen pengkajian M3 (Method) manajemen keperawatan memiliki rata-rata $r$ count $>r$ table $(0,652>$ $0.423)$ dan hasil uji reliabilitas dengan rata-rata $r$ hitung $(0,7843)>0,6$. Hasil evaluasi subjektif 20 responden, $80 \%$ menyatakan instrumen mudah dipahami, $70 \%$ sesuai kebutuhan Rumah Sakit, dan 80\% mudah diaplikasikan. Pengembangan instrumen pengkajian M3 (Method) manajemen keperawatan dinyatakan valid dan reliabel. Instrumen pengkajian M3 (Method) manajemen keperawatan memiliki beberapa kompenen meliputi model MAKP, timbang terima, ronde keperawatan, supervisi, sentralisasi obat, discharge planning. Pengisian instrumen pegkajian tersebut sebaiknya dilakukan secara bertahap oleh perawat sehingga hasilnya dapat menggambarkan kondisi riil Rumah Sakit.
\end{abstract}

Kata Kunci: Instrumen pengkajian, Joint Comission International, Manajemen keperawatan

\begin{abstract}
The assessment methode (M3) in nursing management requires innovation to adapt with room conditions and the requirements of the hospital accreditation standard. The aim of the study was to develop the M3 (Method) assessment instrument in nursing management based on the Joint Commission International accreditation standards. Research Design was mix method combining qualitative and quantitative approaches. The population in this study were all nurses (76) at Amelia Hospital. The sample in this study was 20 nurses with purposive sampling technique. Phase 1 the researcher arranged the instrument through a small group discussion with the nursing field, the head of the room, and the nurse. Stage 2 analyzes the validity and reliability test. The validity test results showed that the
\end{abstract}


M3 (Method) nursing management assessment instrument had an average $r$ count $>r$ table $(0.652>0.423)$ and the reliability test results with an average $r$ count $(0.7843)>0.6$. Subjective evaluation results of 20 respondents, $80 \%$ stated that the instrument was easy to understand, $70 \%$ according to hospital needs, and $80 \%$ was easily applied. The development of a nursing management M3 (Method) assessment instrument was declared valid and reliable. The M3 (Method) instrument for nursing management has several components including the MAKP model, weighing, nursing rounds, supervision, drug centralization, discharge planning. The filling in of the assessment instrument should be carried out in stages by the nurse so the results can describe the real condition of the hospital.

Keywords: Assessment instruments, International Joint Commission, Nursing management

\section{PENDAHULUAN}

tahap $\begin{array}{cr}\text { Mahasiswa keperawatan pada } \\ \text { profesi }\end{array}$
keperawatan memiliki peran yang penting dalam mengkaji kondisi manajemen ruang keperawatan. (Tim KBK AIPNI, 2010). Manajemen keperawatan merupakan pelaksanaan fungsi-fungsi pengelolaan dan pelayanan dalam ruang lingkup keperawatan, mencakup fungsifungsi manajemen seperti perencanaan, organisasi, staffing, pengarahan, dan pengontrolan (Simamora, 2012). Perencanaan disusun berdasarkan hasil pengkajian data informasi tentang pasien, tenaga perawatan, administrasi, model pemberian asuhan keperawatan dan sistem pendokumentasian. Sering terjadinya misperception antara mahasiswa dengan pengelola ruangan pada tahap pengkajian dikarenakan instrument pengkajian manajemen keperawatan sudah ada berupa angket sederhana dan belum memiliki petunjuk cara pengisian lengkap, sehingga pihak pengelola sering beranggapan bahwa instrumen tersebut kurang mewakili kondisi yang terjadi di ruangan.

Pihak pendidikan pada dasarnya sudah menyediakan format pengkajian sebelum pelaksanaan manajemen keperawatan tetapi belum terstandar sehingga kedalaman pengkajian tiap tiap ruang masih sering terdapat perbedaan. Referensi yang terbatas untuk manajeman keperawatan membuat mahasiswa mengalami kesulitan. Perubahan perkembangan yang berkaitan dengan system akreditasi rumah sakit juga memerlukan update terus menerus praktek manajemen agar terdapat keselarasan antara apa yang di siapkan mahasiswa dengan aplikasi di klinik.

Akreditasi adalah pengakuan terhadap Rumah Sakit yang diberikan oleh lembaga independen penyelenggara Akreditasi yang ditetapkan oleh Menteri, setelah dinilai bahwa Rumah Sakit itu memenuhi Standar Pelayanan Rumah Sakit yang berlaku untuk meningkatkan mutu pelayanan Rumah Sakit secara berkesinambungan (Permenkes RI, 2012). Akreditasi JCI (Joint Comission International) adalah salah satu lembaga independen, organisasi non profit yang mengevaluasi dan mengakreditasi organisasi pelayanan kesehatan (Ziegler, 2019). Tujuan diadakannya akreditasi yaitu 1) meningkatkan 
mutu pelayanan Rumah Sakit; 2) meningkatkan keselamatan pasien Rumah Sakit; 3) meningkatkan perlindungan bagi pasien, masyarakat, sumber daya manusia Rumah Sakit dan Rumah Sakit sebagai institusi; 4) mendukung program Pemerintah di bidang kesehatan.

Diperlukan adanya instrumen pengkajian yang valid dan reliabel serta panduan baku dan terstandar dengan petunjuk yang jelas tentang isian pada pengkajian manajemen keperawatan agar dapat digunakan oleh Rumah Sakit serta mahasiswa. Selain itu perlu uji coba dan kesesuaian dengan kebutuhan di klinik yang sesuai dengan standar akreditasi Rumah Sakit (Joint Commission International) agar hasil pengkajian sebagai langkah awal perencanaan manajemen bisa bermanfaat untuk kebutuhan Rumah Sakit sebagai lahan praktek profesi mahasiswa agar mahasiswa tidak tertinggal dengan trend yang terjadi dilapangan (KARS, 2012). Berdasarkan hal tersebut maka peneliti perlu mengembangkan instrumen pengkajian manajemen keperawatan berbasis metode asuhan keperawatan profesional dan standar akreditasi rumah sakit (Joint Commission International)

\section{METODE PENELITIAN}

Desain Penelitian yang digunakan adalah desain mix method research yaitu memadukan pendekatan penelitian kualtatif dan kuantitatif yang terdiri dari 2 tahap. Variabel dalam penelitian ini yaitu pengembangan instrumen pengkajian M3 (Method) manajemen keperawatan berbasis standar akreditasi Joint Commission
International dengan sub variabel yaitu Model Metode Asuhan Keperawatan Profesional, Timbang Terima, Sentralisasi Obat, Penerimaan Pasien Baru, Discharge Planning, Supervisi, dan Ronde Keperawatan.

Pelaksanaan penelitian ini diawali dengan uji etik. Setelah dinyatakan laik etik, dilaksanakan penelitian tahap 1 yaitu menyusun instrumen sesuai standar akreditasi Joint Comission International dengan melakukan SGD (Small Group Discussion) tahap 1 dengan partisipan yaitu pihak bidang keperawatan, kepala ruang, dan sebagian perawat dengan total partisipan sebanyak 10 partisipan. Tahap 2 yaitu melakukan analisis uji validitas dan reliabitas dari instrumen pengkajian M3 (Method) dalam manajemen keperawatan dengan populasi sebanyak 76 perawat. Diperoleh responden sebanyak 20 perawat melalui tehnik purposive sampling.

Alat ukur dalam penelitian ini berupa lembar instrumen pengkajian M3 (Method) yang dikembangkan untuk diuji validitas dan reliabilitas nya. Instrumen pengkajian M3 (Method) dalam manajemen keperawatan yang telah teruji selanjutnya dievaluasi melalui kegiatan SGD (Small Group Discussion) tahap 2 untuk direkomendasikan kepada pihak RS.

Analisis Data terdiri dari 2 tahap yaitu analisis deskriptif dan analisis inferensial. Analisis deskripstif berupa evaluasi subjektif dari partisipan tentang standar isntrument pengkajian M3 (Method) dalam manajemen keperawatan pada saat pelaksanaan Small Group Discussion dan distribusi frekuensi evaluasi responden tentang 
instrumen yang telah dikembangkan. Analisis inferensial berupa uji validitas pengembangan Instrumen pengkajian M3 (Method) dalam manajemen keperawatan berbasis Standar Akreditasi (Joint Commission International) dengan menggunakan Product Moment Pearson Correlation dengan $\alpha 0,05$.
Dasar pengambilan keputusan dari uji ini adalah jika nilai $r$ hitung pada masing-masing item pertanyaan lebih besar dari $r$ tabel maka instrumen tersebut dinyatakan valid. Analisis uji reliabilitas instrumen berdasarkan konsistensi internal dari skala dengan teknik cronbach alpha dengan $\alpha 0,05$ menggunakan program SPSS.

\section{HASIL}

Distribusi frekuensi data umum karakteristik partisipan Small Group Discussion dan responden untuk uji validitas dan reliabilitas bisa dilihat pada tabel 1

Tabel 1: Distribusi frekuensi data umum karakteristik partisipan Small Group

Discussion dan responden untuk uji validitas dan reliabilitas Pengembangan

Instrumen pengkajian M3 (Method) dalam Manajemen Keperawatan Berbasis

Standar Akreditasi Joint Commission International

\begin{tabular}{|c|c|c|c|c|c|}
\hline \multirow[t]{2}{*}{ No. } & \multirow[t]{2}{*}{ Data Umum } & \multicolumn{2}{|c|}{ Partisipan SGD } & \multicolumn{2}{|c|}{ Responden } \\
\hline & & $\mathrm{f}$ & $\%$ & $\mathrm{f}$ & $\%$ \\
\hline \multirow[t]{7}{*}{1} & Usia & & & & \\
\hline & $20-25$ tahun & 0 & 0 & 2 & 10 \\
\hline & 26-30 tahun & 0 & 0 & 4 & 20 \\
\hline & 31-35 tahun & 2 & 20 & 6 & 30 \\
\hline & $36-40$ tahun & 1 & 10 & 1 & 5 \\
\hline & $>40$ tahun & 7 & 70 & 7 & 35 \\
\hline & Total & 10 & 100 & 20 & 100 \\
\hline \multirow[t]{4}{*}{2} & Jenis Kelamin & & & & \\
\hline & Laki-laki & 1 & 10 & 1 & 5 \\
\hline & Perempuan & 9 & 90 & 19 & 95 \\
\hline & Total & 10 & 100 & 20 & \\
\hline \multirow[t]{6}{*}{3} & Lama Kerja & & & & \\
\hline & 1-5 tahun & 0 & 0 & 3 & 15 \\
\hline & 6-10 tahun & 0 & 0 & 4 & 20 \\
\hline & $11-15$ tahun & 3 & 30 & 6 & 30 \\
\hline & $>15$ tahun & 7 & 70 & 7 & 35 \\
\hline & Total & 10 & 100 & 20 & 100 \\
\hline \multirow[t]{4}{*}{4} & Pendidikan terakhir & & & & \\
\hline & D3 Keperawatan & 6 & 60 & 16 & 80 \\
\hline & S1 Keperawatan & 4 & 40 & 4 & 20 \\
\hline & Total & 10 & 100 & 20 & 100 \\
\hline \multirow[t]{4}{*}{5} & Status Pegawai & & & & \\
\hline & Pegawai Tetap & 10 & 100 & 17 & 85 \\
\hline & Pegawai Kontrak & 0 & 0 & 3 & 15 \\
\hline & Total & 10 & 100 & 20 & 100 \\
\hline
\end{tabular}


Berdasarkan tabel 1 di atas, dapat diketahui data umum dari partisipan Small Group Discussion baik tahap 1 dan 2 serta data umum responden untuk uji validitas dan reliabilitas instrumen tahap 2 penelitian. Pada pelaksanaan penelitian tahap 1, sebagian besar partisipan $(70 \%)$ berusia $>40$ tahun, hampir seluruh partisipan (90\%) berjenis kelamin perempuan, sebagian besar partisipan (70\%) bekerja di RS Amelia dengan masa kerja > 15 tahun, sebagian besar partisipan $(60 \%)$ dengan pendidikan terakhir yaitu D3 Keperawatan, seluruh partisipan (100\%) merupakan pegawai tetap RS Amelia Pare Kediri.

Pada pelaksanaan penelitian tahap 2, hampir setengah responden $(35 \%)$ berusia > 40 tahun, hampir seluruh responden $(95 \%)$ berjenis kelamin perempuan, hampir setengah responden $(35 \%)$ bekerja di RS Amelia dengan masa kerja >15 tahun, hampir seluruh responden (80\%) dengan pendidikan terakhir yaitu D3 Keperawatan, dan hampir seluruh responden $(85 \%)$ merupakan pegawai tetap RS Amelia Pare Kediri.

\section{Hasil Penelitian Tahap 1}

Hasil dari kegiatan Small Group Discussion pada penelitian tahap 1 yaitu, para seluruh partisipan sependapat apabila dilakukan pengembangan instrumen pengkajian M3 (Method) dalam Manajemen Keperawatan dikarenakan semakin berkembangnya hal-hal yang harus disesuaikan dengan keperluan standar akreditasi Rumah Sakit. Oleh sebab itu instrumen pengkajian manajemen keperawatan terutama untuk M3 (Method) yang mengkaji kondisi metode dalam asuhan keperawatan pasien pun perlu untuk ikut disesuaikan dengan standar akreditasi Rumah Sakit Joint Commission International. Penting juga selain instrumen dikembangkan, diperlukan panduan/petunjuk pengisian yang jelas dalam pengisian instrumen pengkajian tersebut sehingga tidak lagi terjadi mispersepsi antara pihak mahasiswa dengan pihak ruangan. Terdapat beberapa item pertanyaan yang perlu dirubah atau dilengkapi pada instrumen pengkajian M3 (Method) dalam manajemen keperawatan supaya lebih sesuai dengan istilah yang digunakan saat ini. Misalnya, untuk persetujuan Sentralisasi Obat, awalnya dilakukan saat pasien dirawat di ruang rawat inap, namun saat ini, permohonan persetujuan pelaksanaan sentralisasi obat sudah disampaikan bersamaan dengan General Consent saat pasien tiba di IGD (Instalasi Gawat Darurat) beserta pendokumentasian dari General Consent. Istilah Ronde Keperawatan untuk saat ini yang sesuai dengan Akreditasi Joint Commission International adalah diskusi multidisiplin, dimana secara prosedur tetap sama dengan pelaksanaan ronde keperawatan. Dischrage planning dilaksanakan oleh perawat terutama saat pasien persiapan akan pulang. Penyampaian aturan minum obat saat pasien akan pulang idealnya disampaikan oleh petugas farmasi, sehingga pada saat discharge planning perawat hanya perlu untuk memvalidasi pemahaman pasien tentang aturan minum obat saat di rumah.

\section{Hasil Penelitian Tahap 2}

Hasil uji validitas dan reliabilitas Pengembangan Instrumen pengkajian M3 (Method) dalam 
Manajemen Keperawatan bisa dilihat

pada tabel 2:

Tabel 2: Uji Validitas Pengembangan Instrumen pengkajian M3 (Method) dalam

Manajemen Keperawatan berbasis Standar Akreditasi Joint Commission International

\begin{tabular}{clccc}
\hline No. & Sub Variabel & $\begin{array}{c}\text { Rata-rata } \\
\text { R hitung }\end{array}$ & R Table & Conclution \\
\hline 1 & Model MAKP & 0,874 & 0,423 & Valid \\
\hline 2 & Timbang Terima & 0,519 & 0,423 & Valid \\
\hline 3 & Sentralisasi Obat & 0,440 & 0,423 & Valid \\
\hline 4 & Penerimaan Pasien Baru & 0,513 & 0,423 & Valid \\
\hline 5 & Discharge Planning & 0,832 & 0,423 & Valid \\
\hline 6 & Ronde Keperawatan & 0,738 & 0,423 & Valid \\
\hline & Rata-rata R hitung & $\mathbf{0 , 6 5 2}$ & & Valid \\
\hline
\end{tabular}

Tabel 2 menunjukkan hasil validitas instrumen pengkajian M3 (Method) dalam Manajemen Keperawatan berbasis Standar Akreditasi Joint Commission International melalui uji Product Moment Pearson Correlation dengan tingkat kemaknaan $\alpha 0,05$ pada 20 responden. Pada tabel tersebut terlihat bahwa seluruh item sub variabel memiliki rata-rata $R$ count $>\mathrm{R}$ tabel $(0,423)$ sehingga instrumen pengkajian M3 (Method) dalam Manajemen Keperawatan dinyatakan valid

Tabel 3: Uji Reliabilitas Pengembangan Instrumen pengkajian M3 (Method) dalam Manajemen Keperawatan berbasis Standar Akreditasi Joint Commission International

\begin{tabular}{clccc}
\hline No. & Sub Variabel & R hitung & R Table & Conclution \\
\hline 1 & Model MAKP & 0,831 & 0,423 & Reliabel \\
\hline 2 & Timbang Terima & 0,721 & 0,423 & Reliabel \\
\hline 3 & Sentralisasi Obat & 0,715 & 0,423 & Reliabel \\
\hline 4 & Penerimaan Pasien Baru & 0,825 & 0,423 & Reliabel \\
\hline 5 & Discharge Planning & 0,864 & 0,423 & Reliabel \\
\hline 6 & Ronde Keperawatan & 0,742 & 0,423 & Reliabel \\
\hline & Rata-rata R hitung & $\mathbf{0 , 7 8 3}$ & & Reliabel \\
\hline
\end{tabular}

Tabel 3 menunjukkan hasil reliabilitas instrumen pengkajian M3 (Method) dalam Manajemen Keperawatan berbasis Standar Akreditasi Joint Commission International melalui uji cronbach alpha dengan tingkat kemaknaan $\alpha$ 0,05 pada 20 responden. Pada tabel tersebut terlihat bahwa seluruh item sub variabel memiliki rata-rata $R$ hitung > $\mathrm{R}$ Tabel atau rata-rata nilai cronbach alpha $>0,6$ sehingga instrumen pengkajian M3 (Method) dalam Manajemen Keperawatan dinyatakan reliable. Hasil evaluasi subjektif 20 responden dalam penelitian, $80 \%$ menyatakan instrumen mudah dipahami, $70 \%$ sesuai dengan kebutuhan Rumah Sakit, dan $80 \%$ mudah diaplikasikan. 


\section{PEMBAHASAN}

\section{Small Group Discussion} (SGD) dilaksanakan sebelum uji coba instrumen. Hal tersebut bertujuan supaya peneliti mendapatkan masukan dari pihak rumah sakit tentang kesesuaian antara isian dalam instrument pengkajian M3 (Method) dalam Manajemen keperawatan dengan kondisi dan kebutuhan yang ada di Rumah Sakit saat ini. Hasil dari SGD yaitu seluruh partisipan sependapat apabila dilakukan pengembangan instrumen pengkajian M3 (Method) dalam Manajemen Keperawatan dikarenakan semakin berkembangnya hal-hal yang harus disesuaikan dengan keperluan standar akreditasi Rumah Sakit. Sebagai contohnya yaitu perubahan beberapa kata atau kalimat dalam instrumen yaitu persetujuan Sentralisasi Obat, awalnya dilakukan saat pasien dirawat di ruang rawat inap, namun saat ini, permohonan persetujuan pelaksanaan sentralisasi obat sudah disampaikan bersamaan dengan General Consent saat pasien tiba di IGD (Instalasi Gawat Darurat) beserta pendokumentasian dari General Consent. Istilah Ronde Keperawatan untuk saat ini yang sesuai dengan Akreditasi Joint Commission International adalah diskusi multidisiplin, dimana secara prosedur tetap sama dengan pelaksanaan ronde keperawatan. Dischrage planning dilaksanakan oleh perawat terutama saat pasien persiapan akan pulang. Penyampaian aturan minum obat saat pasien akan pulang dalam discharge planning idealnya disampaikan oleh petugas farmasi, sehingga pada saat discharge planning, perawat hanya perlu untuk memvalidasi pemahaman pasien tentang aturan minum obat saat di rumah.

Akreditasi adalah pengakuan terhadap Rumah Sakit yang diberikan oleh lembaga independen penyelenggara Akreditasi yang ditetapkan oleh Menteri, setelah dinilai bahwa Rumah Sakit itu memenuhi Standar Pelayanan Rumah Sakit yang berlaku untuk meningkatkan mutu pelayanan Rumah Sakit secara berkesinambungan (Permenkes RI, 2012). Akreditasi JCI (Joint Comission International) adalah salah satu lembaga independen, organisasi non profit yang mengevaluasi dan mengakreditasi organisasi pelayanan kesehatan (Ziegler, 2019). Tujuan diadakannya akreditasi yaitu 1) meningkatkan mutu pelayanan Rumah Sakit; 2) meningkatkan keselamatan pasien Rumah Sakit; 3) meningkatkan perlindungan bagi pasien, masyarakat, sumber daya manusia Rumah Sakit dan Rumah Sakit sebagai institusi; 4) mendukung program Pemerintah di bidang kesehatan.

Setiap Rumah sakit wajib untuk melaksanakan akreditasi. Hal tersebut penting untuk dilakukan supaya pasien mendapat pelayanan terbaik selama dirawat di Rumah Sakit. Sesuai dengan yang dikemukakan oleh National Guard Health Affairs (NGHA), JCI Accreditation is the most sought after accreditation due to the thoroughness of its process that covers everything from patient entry to discharge and asses all aspects of management, to meet the standards of the best Hospital in the world (NGHA, 2014). Oleh sebab itu setiap rumah sakit perlu untuk memanajemen rumah sakitnya supaya bisa memperoleh 
hasil akreditasi yang baik dari lembaga akreditasi nasional maupun internasional. Isntrumen pengkajian bermanfaat untuk sinkronisisasi antara pihak pengelelola rumah sakit dan pihak pendidikan, agar hasil pengkajian mahasiswa selama praktek manajemen keperawatan dapat digunakan sebagai bahan evaluasi dan masukan dalam menentukan kebijakan bagi pihak rumah sakit. Apabila instrumen pengkajian yang digunakan oleh mahasisswa valid dan reliabel serta sesuai dengan kebutuhan rumah sakit, maka keberadaan praktek mahasiswa profesi akan sangat membantu pihak rumah sakit dalam memanagemen ruangannya.

Hasil penelitian sesuai dengan tabel 2 menyatakan bahwa nilai rata-rata $r$ hitung yaitu model MAKP 0,874 , Timbang terima 0,519, Sentralisasi Obat 0,440, Penerimaan pasien baru 0,513, Disharge planning 0,832, Ronde Keperawatan 0,738 dimana secara keseluruhan $>\mathrm{r}$ tabel $(0,423)$ yang artinya instrumen pengkajian M3 (Method) dalam Manajemen Keperawatan dinyatakan valid.

Hasil uji reliabilitas untuk MAKP 0,831, Timbang terima 0,721, Sentralisasi Obat 0,715, Penerimaan pasien baru 0,865, Disharge planning 0,864, Ronde Keperawatan 0,742 dimana secara keseluruhan $>\mathrm{r}$ tabel $(0,423)$ dan lebih besar dari 0,6 sehingga dinyatakan reliabel. Hasil evaluasi subjektif 20 responden dalam penelitian, $80 \%$ menyatakan instrumen mudah dipahami, 70\% sesuai dengan kebutuhan Rumah Sakit, dan $80 \%$ mudah diaplikasikan

Nursalam

mengemukakan bahwa pengkajian manajemen keperawatan terdiri dari
5M yaitu M1 (Man), M2 (Material), M3 (Method), M4 (Money), M5 (Mutu). Pengkajian M3 (Method) berisi tentang pengkajian metode suatu ruangan dalam memberikan asuhan keperawatan kepada pasien mulai dari pasien masuk hingga pasien pulang. Yang dibahas dalam M3 yaitu mulai dari model MAKP (Metode Asuhan Keperawatan Profesional), Timbang Terima, Sentralisasi Obat, Penerimaan Pasien Baru, Discharge Planning, Supervisi, dan Ronde Keperawatan (Nursalam, 2017).

Sistem MAKP adalah suatu kerangka kerja yang mendefinisikan keempat unsur: standart, proses keperawatan, pendidikan keperawatan dan sistem MAKP. Definisi tersebut berdasarkan prinsip- prinsip nilai yang diyakini dan akan menentuakan kualitas produksi/ jasa layanan keperawatan (Gillis, 2000). Keberhasilan suatu asuhan keperawatan kepada pasien sangat ditentukan oleh pemilihan metode pemberian asuhan keperawatan profesional. Dasar pertimbangan pemilihan Model MAKP menurut Nursalam (2017) yaitu 1) Sesuai dengan visi misi Institusi; 2) Dapat diterapkan proses keperawatan dalam asuhan keperawatan; 3) Efisien dan efektif dalam penggunaan biaya; 4) Terpenuhinya kepuasan pasien keluarga dan masyarakat; 5) Kepuasan dan kinerja perawat; 6) Terlaksananya komunikasi yang adekuat antara perawat dan tim kesehatan lainnya. Sesuai dengan dasar pertimbangan pemilihan model MAKP tersebut, instrumen pengkajian untuk model MAKP disusun. Hasil uji instrumen dinyatakan valid setelah menghilangkan 2 item soal yang 
awalnya dinyatakan tidak valid dikarenakan 2 item soal dalam pertanyaan yang diajukan kurang bisa menggambarkan kondisi model MAKP yang dimaksud.

Timbang terima (Hand Over) merupakan teknik atau cara untuk menyampaikan dan menerima sesuatu (laporan) yang berkaitan dengan keadaan pasien. Hal-hal yang dijadikan dasar dalam pembuatan instrumen pengkajian timbang terima yaitu mengacu pada hal-hal yang perlu diperhatikan dalam timbang terima menurut Nursalam (2017) yaitu 1) dilaksanakan tepat pada waktu pergantian sift; 2) dipimpin oleh kepala ruangan atau penanggung jawab pasien; 3) diikuti oleh semua perawat; 4) informasi yang disampaikan akurat; 5) berorientasi pada permasalahan pasien; 6) timbang terima juga perlu dilakukan menuju ke kamar pasien untuk validasi keadaan pasien.

Ronde

keperawatan

merupakan kegiatan yang bertujuan untuk mengatasi masalah keperawatan pasien yang dilaksanakan oleh perawat melibatkan pasien dan seluruh tim kesehatan untuk membahas dan melaksanakan asuhan keperawatan (Nursalam 2017). Istilah ronde keperawatan sekarang lebih dikenal dengan istilah diskusi multidisiplin / kolaborasi interprofesional. Praktik interdisiplin atau kolaborasi interprofesional merupakan kerjasama kemitraan dalam tim kesehatan yang melibatkan profesi kesehatan dan pasien, melalui koordinasi dan kolaborasi untuk pengambilan keputusan bersama seputar masalah-masalah kesehatan ( Susilaningsih dkk, 2017). Model Praktik Kolaborasi Interprofesional Pelayanan kesehatan (MPKIPK) merupakan tatanan pelayanan yang dirancang untuk menyelaraskan berbagai profesi yang terlibat (antara lain dokter, perawat, farmasi, dan gizi) dalam memberikan pelayanan kepada pasien yang menjalani hospitalisasi. Model ini terdiri dari 4 komponen yaitu alur klinis pengelolaan pasien (integrated care pathway), pengelolaan pasien secara tim, dokumentasi asuhan terpadu dan penyelesaian masalah bersama melalui diskusi kasus secara interprofesional (Susilaningsih $\mathrm{dkk}$, 2017). Penyusunan instrumen pengkajian ronde keperawatan yang dibuat berdasarkan konsep tersebut disesuaikan dengan acuan dari standar akreditasi Rumah Sakit yang digunakan saat ini.

Sentralisasi obat merupakan pengelolaan obat dimana seluruh obat yang akan diberikan kepada pasien diserahkan sepenuhnya kepada perawat, pengeluaran dan pembagian obat sepenuhnya oleh perawat (Nursalam, 2017). Secara prosedur, sentralisasi obat dikenalkan kepada pasien bersamaan pada saat penerimaan pasien baru. Namun dalam perkembangannya saat ini, persetujuan dari pelaksanaan sentralisasi obat dilaksanakan pada saat pasien berada di ruang IGD, bersamaan dengan "general consent". Berbeda dengan sebelumnya, persetujuan sentralisasi obat dilakukan di ruang rawat inap. Dalam sentralisasi obat, tidak hanya melibatkan perawat saja, tetapi juga melibatkan petugas farmasi dalam pengelolaan obat. Selain itu juga perawat perlu untuk meminta tanda tangan kepada pasien atau keluarga supaya dijadikan sebagai bukti bahwa obat telah diberikan dengan tepat kepada pasien oleh perawat. Instrumen pengkajian tentang 
pelaksanaan Sentralisasi obat digunakan untuk menilai sejauh mana sentralisasi obat dilaksanakan sesuai dengan prosedur pelaksanaan sentralisasi obat serta menggambarkan kondisi ruangan dalam pengelolaan sentralisasi obat. Discharge planning merupakan bagian dari asuhan keperawatan yang dilakukan sebagai upaya pemberian pelayanan yang berkelanjutan yaitu pelayanan di rumah sakit dimulai sejak pasien masuk sampai pasien pulang (Nursalam, 2017). Discharge planning berisi tentang pemberian edukasi kepada pasien tentang penyakit pasien sehingga dengan adanya edukasi tersebut pasien memahami tentang penyakitnya. Pelaksanaan discharge planning sejalan dengan stnadar akreditasi Rumah Sakit dimana Pendidikan Pasien dan Keluarga menjadi hal yang penting dalam penilaian. Dengan dilaksanakannya discharge planning atau pendidikan kesehatan kepada pasien dan keluarga maka dapat menigkatkan pengetahuan pasien dan keluarga sehingga bisa menunjang pastisipasi pasien dan keluarga dalam pengambilan keputusan dan proses pelayanan (Standar Akreditasi Rumah Sakit, 2011). Instrumen pengkajian pelaksanaan Dischrage planning diharapkan mampu menggambarkan konsistensi ruangan keperawatan dalam pemberian pendidikan kesehatan pada pasien dan keluarga.

Semua instrumen yang disusun telah diuji validitas dan reliabilitas nya didasarkan pada kebutuhan akan pemenuhan standar akreditasi Rumah Sakit Join Comission International. Jika terdapat soal didalam instrumen yang belum valid, maka upaya dari peneliti adalah mengganti bentuk pertnyaannya atau menghilangkan pertanyaan tersebut.

Sesuai dengan hasil evaluasi subjektif dari responden, dimana hampir seluruh responden menyatakan bahwa instrumen mudah dipahami, mudah diaplikasikan dan sesuai dengan kebutuhan Rumah Sakit. Hal tersebut lah yang juga ikut mendukung terbentuknya instrumen yang valid dan reliabel dari instrumen pengkajian M3 (Method) dalam pengkajian manajemen keperawatan.

\section{SIMPULAN}

Instrumen pengkajian M3 (Method) dalam manajemen keperawatan berbasis Standar Akreditasi Joint Commission International yang terdiri dari instrumen pengkajian Model Metode Asuhan Keperawatan Profesional, Timbang Terima, Sentralisasi Obat, Penerimaan Pasien Baru, Discharge Planning, Supervisi, Ronde Keperawatan, dan Dokumentasi Keperawatan dinyatakan valid dan reliabel.

\section{SARAN}

Disarankan pada saat pengisian instrumen pegkajian tersebut sebaiknya dilakukan secara bertahap dikarenakan isian pengkajian yang cukup banyak agar instrumen diisi dengan jujur sehingga hasil jawaban yang diisi oleh perawat bisa menggambarkan kondisi sebenarnya yang dialami oleh Rumah Sakit. 


\section{DAFTAR PUSTAKA}

Azizah, Widayati, Rachmania, (2016). Pengaruh Discharge Planning terhadap Kualitas Pelayanan Keperawatan di Rumah Sakit Amelia Pare Kediri. Journals of Nurse Community, Volume 8 Nomor 1. ISSN : 2541-2957

Gillis, DA.(2000). Manajemen Keperawatan: Sebagai Suatu Pendekatan Sistem. Bandung: IAIKP

Huber, Diane L. (2010). Leadership and Nursingcare Management, fourth edition, Philadelphia: Sounders Elseiver.

Kementrian Kesehatan RI, 2011, Standar Akreditasi Rumah Sakit, Jakarta: Kementrian Kesehatan RI

Komisi Akreditasi Rumah Sakit 2012, Panduan Survei, Komisis Akreditasi Rumah Sakit, Jakarta: Komisi Akreditasi Rumah Sakit

Kurniadi, Anwar (2013). Manajemen Keperawatan dan Prospektifnya, Jakarta, Badan FKUI.

Mahlinda, 2010, Instrumen penelitian. http://mahlindasetulushati.blogspot.co.id/201 0/06/instrumenpenelitian.html. Diakses 3 Agustus 2018.

NGHA (National Guard Health Affairs), 2014. Define Accreditation in Medical Cities. www.ngha.med.sa/English/A boutNGHA/Pages/Accreditati on.aspx. Diakses tanggal 20 Agustus 2019

Nursalam, (2013), Metodologi Penelitian Ilmu Keperawatan, Salemba Medika, Jakarta

Nursalam, (2017). Manajemen Keperawatan: Aplikasi Dalam Prakyik Keperawatan Profesional, Jakarta, Salemba Medika

Okaisu, E.M., Kalikwani, F., Wanyana, G. \& Coetzee, M., 2014, Improving the quality of nursing documentation: An action research project', Curationis 38(1), Art. \#1251, 11 pages. http://dx.doi. org/10.4102/curationis. v37i1.1251. Diakses Tanggal 3 Agustus 2018

Peraturan Pemerintah Republik Indonesia No.4 Tahun 2014 tentang Penyelenggaraan Pendidikan Tinggi dan Pengelolaan Perguruan Tinggi

Polit, D.F. \& Hungler, B.P, 1997, Essential of Nursing Reserach: Method, apraisal, and utilization. Fourth edition. Philadelphia: Lippincot

Rachmania, Nursalam, Yunitasari. 2016. Pengembangan Instrumen Diagnosis dan Intervensi Keperawatan berbasis Standardized Nursing Language (NANDAI, NOC, NIC). JURNAL NERS Vol. 11/No.2/Published: 2016-10. E-ISSN: 2502-5791 
Simamora, Roymond H. 2012. Buku

Ajar Manajemen

Keperawatan. Jakarta. EGC

Staub, M.M., Lunney, M., Lavin M.A., Needham, I., Odenbreit,M., Achterberg, Tv, 2008, Testing the Q-DIO as an instrument to measure the documented quality of nursing diagnosis, intervention, and outcomes. International Journal of Nursing Terminologies and Classifications; 19, 1
Wang N. , Hailey D. \& Yu P, 2011, Quality of nursing documentation and approaches to its evaluation: a mixed-method systematic review. Journal of Advanced Nursing 00(0), 000-000. doi: $10.1111 / \mathrm{j} .1365-$ 2648.2011.05634.x. Diakses Tanggal 6 Agustus 2018

Ziegler, Helen, 2019. What is JCI Acreditation.

www.hziegler.com. Diakses tanggal 20 Agustus 2019 